\title{
Wind Erosion Climate Change in Northern China During 1981-2016
}

\author{
Feng Zhang ${ }^{1,2,3} \cdot$ Jing'ai Wang ${ }^{1,2} \cdot$ Xueyong Zou ${ }^{1,2,3} \cdot$ Rui Mao ${ }^{1,2,3}$. \\ Daoyi Gong ${ }^{1,2,3} \cdot$ Xingya Feng ${ }^{2}$
}

Published online: 28 July 2020

(C) The Author(s) 2020

\begin{abstract}
Wind erosion is largely controlled by climate conditions. In this study, we examined the influences of changes in wind speed, soil wetness, snow cover, and vegetation cover related to climate change on wind erosion in northern China during 1981-2016. We used the wind erosion force, defined as wind factor in the Revised Wind Erosion Equation Model, to describe the effect of wind speed on wind erosion. The results show that wind erosion force presented a long-term decreasing trend in the southern Northwest, northern Northwest, and eastern northern China during 1981-2016. In the Gobi Desert, the wind erosion force presented for 1981-1992 a decreasing trend, for 1992-2012 an increasing trend, and thereafter a weakly decreasing trend. In comparison to wind speed, soil wetness and snow cover had weaker influences on wind erosion in northern China, while vegetation cover played a significant role in the decrease of wind erosion in the eastern northern China during 1982-2015.
\end{abstract}

Keywords Northern China $\cdot$ RWEQ model $\cdot$ Wind erosion - Wind erosion force - Heavy wind frequency

Rui Mao

mr@bnu.edu.cn

1 State Key Laboratory of Earth Surface Processes and Resource Ecology, Faculty of Geographical Science, Beijing Normal University, Beijing 100875, China

2 Faculty of Geographical Science, Beijing Normal University, Beijing 100875, China

3 MOE Engineering Research Center of Desertification and Blown-Sand Control, Faculty of Geographical Science, Beijing Normal University, Beijing 100875, China

\section{Introduction}

Wind erosion occurs in arid and semiarid areas in China, which cover approximately $165.59 \times 10^{4} \mathrm{~km}^{2}$ and constitute $17.25 \%$ of the national territory (Shi et al. 2004; China 2013). Wind erosion is influenced by climatic conditions, soil erodibility, and anthropogenic activities. Climatic conditions include wind speed, precipitation, relative humidity, and snow cover (Fryrear et al. 1998; Shao et al. 2013). Soil erodibility is influenced by vegetation cover and soil texture, crust, and organic carbon. Anthropogenic activities mainly include land use that results in changes in vegetation cover (Mao et al. 2013; Chi et al. 2019).

Many studies have analyzed the causes of change in wind erosion in northern China during recent decades (Dong and Kang 1994; Yang and Lu 2016; Han 2019). Yang and Lu (2016) and Han (2019) used wind erosion climatic erosivity, indicated as a revised $\mathrm{C}$ factor from the Food and Agriculture Organization (FAO) of the United Nations (1979), to assess the effects of wind speed and soil wetness on wind erosion in northern China. These sources reported decreased wind erosion climatic erosivity and wind erosion in northern China during 1961-2012. In addition to the wind erosion climatic erosivity, some authors used the climatic factor in the Revised Wind Erosion Equation (RWEQ) model to assess the effects of wind speed, soil wetness, and snow cover on wind erosion (Fryrear et al. 1998). Based on the RWEQ model, a decrease in wind erosion in northern China was ascribed to a decrease in the climatic factor of the RWEQ model during 1990-2000 (Zhang et al. 2018; Chi et al. 2019). Besides climatic conditions, changes in vegetation cover caused by human activities and natural climate change exerted influences on wind erosion in northern China 
(Huang et al. 2018; Zhang et al. 2018; Chi et al. 2019; Wu et al. 2019; Zhao et al. 2020).

Although these studies emphasized the influences of wind speed, soil wetness, snow cover, and vegetation cover on wind erosion, wind speed is ascribed as a critical factor that results in the decrease in wind erosion in northern China (Du et al. 2017; Zhang et al. 2018; Chi et al. 2019). The aim of this study is to examine the changes in wind speed and their impacts on wind erosion in northern China during 1981-2016. To highlight the critical role of wind speed in changes in wind erosion, wind erodibility related to climate change was analyzed as well. The influence of soil wetness, snow cover, and vegetation cover on wind erosion was also examined. The remainder of this article is structured as follows. Section 2 briefly describes the study area, data, and method. Changes in wind speed, extreme wind speed, and wind erosion force in northern China are presented in Sect. 3. We discuss two issues in Sect. 4: (1) the influence of soil wetness and snow cover on wind erosion in northern China; and (2) the role of vegetation cover in the changes in wind erosion in northern China. Finally, in Sect. 5 the conclusion is provided.

\section{Study Area, Data, and Method}

In this section, we describe the study area and sources of meteorological data, snow cover data, and vegetation cover data. Moreover, to examine the changes in wind erosivity and erodibility in northern China related to climate change, we provide the calculation procedures of wind erosion force and climatic factor of the RWEQ model.

\subsection{Study Area and Data}

In this study, wind erosion area in northern China was analyzed (enclosed by a red contour line in Fig. 1); this area includes arid areas in Northwest China and the west of central-northern China (annual precipitation less than $200 \mathrm{~mm}$ ), semiarid areas in the east of central-northern China (annual precipitation between 200 and $400 \mathrm{~mm}$ ), and subhumid areas in Northeast China (annual precipitation more than $400 \mathrm{~mm}$ ) (Wang 2007).

The meteorological data include hourly wind speed at $10 \mathrm{~m}$ above the ground, daily air temperature, daily precipitation, and daily sunshine hours, which were obtained from the National Climate Center of the China Meteorological Administration. ${ }^{1}$ The meteorological data were observed at nearly 270 stations during the period from 1981 to 2016. The daily snow cover data were obtained

\footnotetext{
$\overline{1}$ http://data.cma.cn/data/cdcdetail/dataCode/SURF_CLI_CHN_ MUL_DAY.html.
}

from the Environmental and Ecological Science Data Center for West China with a period of 2000-2016 at a spatial resolution of $0.25^{\circ} \times 0.25^{\circ}$. To examine the influence of vegetation cover on wind erosion, vegetation cover was represented by the Normalized Difference Vegetation Index (NDVI) from the Global Inventory Monitoring and Modeling System (GIMMS). The satellite-based NDVI products were obtained from $8 \mathrm{~km}$ and 15-day composite GIMMS3g data for the period 1981-2015 (Tucker et al. 2005; Pinzon and Tucker 2014). ${ }^{2}$

We first screened meteorological data because there were many missing records in the hourly wind speed data. For a given station and a given day, when the number of records in the given day was larger than 12, the records in the given day were retained at the given station. Subsequently, because every half-month was regarded as a calculation period, only stations with missing records less than $20 \%$ of observations in the half-month were retained. As a result, there were 127 stations used in the analysis. In addition, for a given station, its snow cover was set to be an average of snow cover of grids around the given station. The distance between the given station and its surrounding grids was less than $0.25^{\circ}$.

\subsection{Methods}

In this study, we used wind erosion force to describe wind erosivity decided by wind speed. We defined the wind factor (Wf) in the RWEQ model to measure the magnitude of wind erosion force, although there are different forms of wind erosion prediction models, including the RWEQ, wind erosion prediction system (WEPS), and wind erosion stochastic simulator (WESS) model. The choice of $W f$ is based on two points. (1) The RWEQ model directly provides the $W f$ to describe the influence of wind speed on wind erosion, which can be readily used. In contrast to the RWEQ model, the WEPS and WESS models do not give individual factors ascribed to the influence of wind speed on wind erosion. (2) The WEPS and WESS require detailed input data about a study area's weather, soil surface conditions, vegetation, and management, which may not be possible to obtain even for a small area (Wagner 2013; Jarrah et al. 2020). The RWEQ model requires fewer parameters compared to the WEPS and WESS and can be scaled up. Therefore, the RWEQ model has not only been successfully applied in the United States (Van Pelt et al. 2004), but also has been widely used in other geographical environments such as Argentina (Buschiazzo and Zobeck 2008), Egypt (Fryrear et al. 2008), and China (Guo et al. 2013).

\footnotetext{
${ }^{2}$ https://ecocast.arc.nasa.gov/data/pub/gimms/3gv0/.
} 


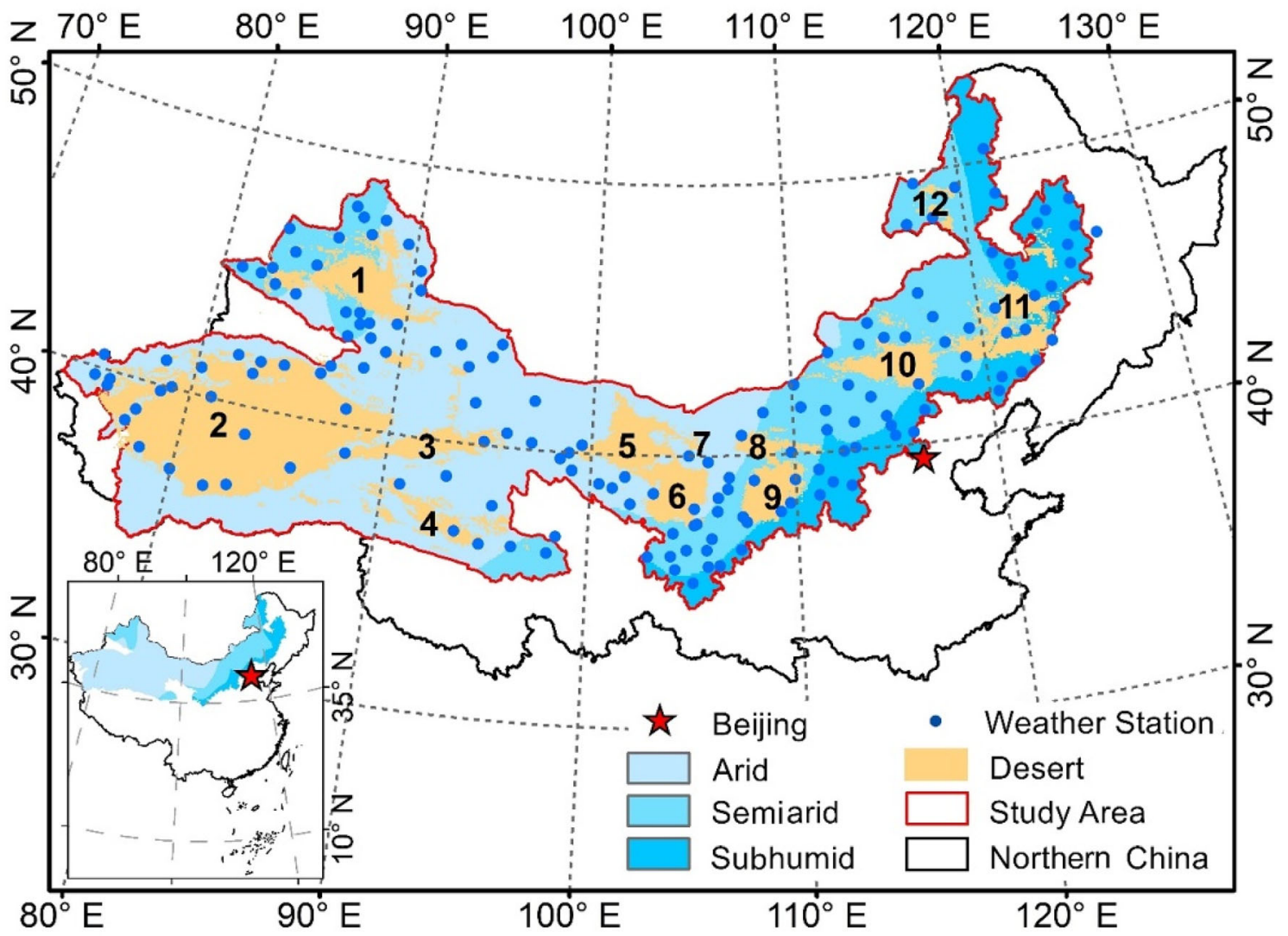

Fig. 1 Location of the study area, meteorological stations, deserts, and sandy lands in northern and western China. The study area is enclosed by a red contour line. Deserts and sandy lands are indicated by numbers: the Gurbantunggut Desert (1), the Taklimakan Desert (2), the Kumtag Desert (3), the Desert in Qaidam Basin (4), the Badain Jaran Desert (5), the Tengger Desert (6), the Ulan Buh Desert

In the calculation of the $W f$, hourly wind speed was taken into account, because wind erosion was initiated by high wind speed, which was typically higher than the threshold wind speed (Guo et al. 2012; Shen et al. 2018). For a given period, the $W f$ (unit: $\mathrm{m}^{3} \mathrm{~s}^{-3}$ ) is determined by Eq. 1, where $U_{2}$ is wind speed at $2 \mathrm{~m}$ above the surface at a hourly time scale (Guo et al. 2012), which is calculated from wind speed at $10 \mathrm{~m}\left(\mathrm{U}_{10}\right)$ above the surface by using Eq. 2 of Elliott (1979); $U_{t}$ is the threshold wind speed at $2 \mathrm{~m}$ and is assumed at $5 \mathrm{~m} \mathrm{~s}^{-1} ; N$ is the number of wind observations in the given period; $N_{d}$ is the number of days in the given period. Fryrear et al. (1998) suggested that $N$ should be 500, but we used the real number of wind observations in this study. Although $U_{t}$ varies between the regions in northern China, we followed Fryrear et al. (1998) to use $5 \mathrm{~m} \mathrm{~s}^{-1}$ in the calculation of $W f$ for convenience. In addition, to explain the variations of $W f$, we analyzed heavy wind frequency defined as the ratio of frequency of hourly wind speed exceeding $5 \mathrm{~m} \mathrm{~s}^{-1}$ to the total number of hourly wind observations ( $\mathrm{Li}$ et al. 2018).
(7), the Hobq Desert (8), the Mu Us Sandy Land (9), the Otindag Sandy Land (10), the Horqin Sandy Land (11), and the Hulunbuir Sandy Land (12). The shaded blue areas are the arid areas, semiarid areas, and subhumid areas in northern China, respectively. Source: After Shi et al. (2004)

$W f=\frac{\sum_{i=1}^{N} U_{2}\left(U_{2}-U_{t}\right)^{2}}{N} N_{d}$

$U_{2}=U_{10}\left(\frac{2}{10}\right)^{\frac{1}{7}}$

In Sect. 4, we discussed changes in the erodibility of soil by wind erosion in northern China related to climate change. First, the influence of soil wetness and snow cover on wind erosion was analyzed by calculating the climatic factor $(C F)$ in the RWEQ model. The $C F$ is calculated by multiplication of $W f$, soil wetness factor $(S W)$, and snow cover factor $(S D)$, as in Eq. 3, where $\rho$ is air density $\left(\mathrm{kg} \mathrm{m}^{-3}\right)$ and $g$ is acceleration due to gravity $\left(\mathrm{m} \mathrm{s}^{-2}\right)$. The $S W$ (dimensionless) is quantified by Eqs. $4-8$, where $R$ is precipitation $(\mathrm{mm})$ and $I$ is irrigation amount-set to zero; $R_{d}$ is the number of days of precipitation; and $E T_{p}$ is potential evapotranspiration $(\mathrm{mm})$ determined by $S R$ (total solar radiation for the given period, cal $\mathrm{cm}^{-2} \mathrm{day}^{-1}$ ) and $D T$ (average temperature, ${ }^{\circ} \mathrm{C}$ ). $S R$ is calculated by $R a$ (extraterrestrial radiation for a daily period, 
MJ $\mathrm{m}^{-2}$ day $^{-1}$ ), where 24 is the number of hours per day, 60 is the number of minutes per hour, $G_{s r}$ is the solar constant $\left(\mathrm{MJ} \mathrm{m}^{-2} \mathrm{~min}^{-1}\right), d_{r}$ is inverse relative distance Earth-Sun, $\omega_{s}$ is the sunset hour angle $(\mathrm{rad}), \varphi$ is the latitude of the station (rad), $\delta$ is the solar decimation (rad), and $n$ is the sunshine hour. Note that $R a$ is expressed in $\mathrm{MJ} \mathrm{m}^{-2}$ day $^{-1}$. The corresponding equivalent evaporation in cal $\mathrm{cm}^{-2}$ day $^{-1}$ is obtained by multiplying $R a$ by 23.889. The Angstrom values $a_{s}$ and $b_{s}$ vary depending on atmospheric conditions (humidity and dust) and solar declination (latitude and month). Because no actual solar radiation data were available and no calibrations had been carried out to improve the $a_{s}$ and $b_{s}$ parameters, the $a_{s}$ and $b_{s}$ are recommended to be 0.25 and 0.50 , respectively (Allen et al. 1998). The $S D$ is equal to 1 minus the probability that snow depth is greater than $25.4 \mathrm{~mm}$, quantified by Eq. 9. Because of inadequate snow cover data before 2000, climatological SD in 2000-2016 was used in CF calculation for 1981-1999. Following calculation procedures outlined in Fryrear et al. (1998), a month was evenly separated into two parts and every halfmonth was defined to be the calculation period. In addition to soil wetness and snow cover, the influence of vegetation cover on wind erosion in northern China was assessed by analyzing long-term trends in NDVI in northern China for the period 1981-2015. In this study, to highlight the spatial discrepancy in wind erosion force in northern China, we separated northern China into four subregions-southern Northwest China (SNWC), northern Northwest China (NNWC), Gobi Desert, and eastern northern China (ENC). Spring season was examined and monthly variables in March to May were aggregated for the spring season by averaging them.

$$
\begin{aligned}
& C F=W f \times \frac{\rho}{\mathrm{g}} \times S W \times S D \\
& S W=\frac{E T_{p}-(R+I) \frac{R_{d}}{N_{d}}}{E T_{p}} \\
& E T_{p}=0.0162\left(\frac{S R}{58.5}\right)(D T+17.8) \\
& R_{a}=\frac{24(60)}{\pi} G_{s r} d_{r}\left[\omega_{s} \sin (\varphi) \sin (\delta)+\cos (\varphi) \cos (\delta) \sin \omega_{s}\right]
\end{aligned}
$$

$S R=\left(a_{s}+b_{s} \times \frac{n}{N}\right) \times R_{a}$

$N=\frac{24}{\pi} \omega_{s}$

$S D=1-P($ snow cover $>25.4 \mathrm{~mm})$

\section{Changes in Wind Erosion Force in Northern China During 1981-2016}

The following sections present changes in mean wind speed, extreme wind speed, and wind erosion force in northern China during 1981-2016. First, spatial distributions of the climatological mean wind speed and trends in mean wind speed in northern China are presented. Then, regional mean wind speed is compared among the four subregions in northern China (Sect. 3.1). This section also shows spatial distributions of climatological mean wind speed of heavy wind (defined in Sect. 3.2) and trends in mean wind speed of heavy wind in northern China. The regional mean of heavy wind frequency is presented for the four subregions as well (Sect. 3.2). Finally, spatial distributions of the climatological wind erosion force and trend in wind erosion force and regional wind erosion force of the four subregions are combined to evaluate changes in the impact of wind speed on wind erosion in northern China during 1981-2016 (Sect. 3.3).

\subsection{Changes in Mean Wind Speed}

Figure $2 \mathrm{a}$ shows the spatial distribution of the climatology of mean wind speed in spring in northern China during 1981-2016. The results show that mean wind speed was higher in the NNWC, the Gobi Desert, and ENC than the SNWC in spring. The mean wind speed was 1.7, 2.5, 2.6, and $2.7 \mathrm{~m} \mathrm{~s}^{-1}$ in the SNWC, NNWC, Gobi Desert, and ENC in spring from 1981 to 2016, respectively. Spatially, the highest mean wind speed occurred along the boundary between China and Mongolia, mainly over the northern Gobi Desert and the eastern part of the ENC at above $3 \mathrm{~m} \mathrm{~s}^{-1}$. The spatial distribution of high mean wind speed is consistent with high wind erosion in spring, supporting a dominant role of mean wind speed in influencing wind erosion in northern China (Chi et al. 2019).

Figure $2 b$ shows the spatial feature of linear trends in mean wind speed in northern China during spring from 1981 to 2016. The results show that nearly all northern China was featured by a decreasing trend in mean wind speed by more than $-0.1 \mathrm{~m} \mathrm{~s}^{-1}$ per 10 year. The largest decreasing trend in mean wind speed was found in the NNWC, the boundary between the SNWC and the Gobi Desert, and the eastern part of the ENC by more than $-0.3 \mathrm{~m} \mathrm{~s}^{-1}$ per 10 year. The central and western parts of the ENC showed a decreasing trend by $-0.2 \mathrm{~m} \mathrm{~s}^{-1}$ per 10 year. In contrast to the widespread of decreasing trends in mean wind speed in northern China, the Gobi Desert showed a weak increasing trend in mean wind speed by more than $0.1 \mathrm{~m} \mathrm{~s}^{-1}$ per 10 year, indicating an increasing influence of wind speed on wind erosion. 
Fig. 2 Spatial distribution of climatological wind speed (a), trends in mean wind speed (b), mean wind speed of heavy wind (c), and heavy wind frequency (d) in spring over northern China during 1981-2016. The southern Northwest China (SNWC), northern Northwest China (NNWC), Gobi Desert, and eastern northern China (ENC) are enclosed by solid lines in (a) (a) Climatology of mean wind speed

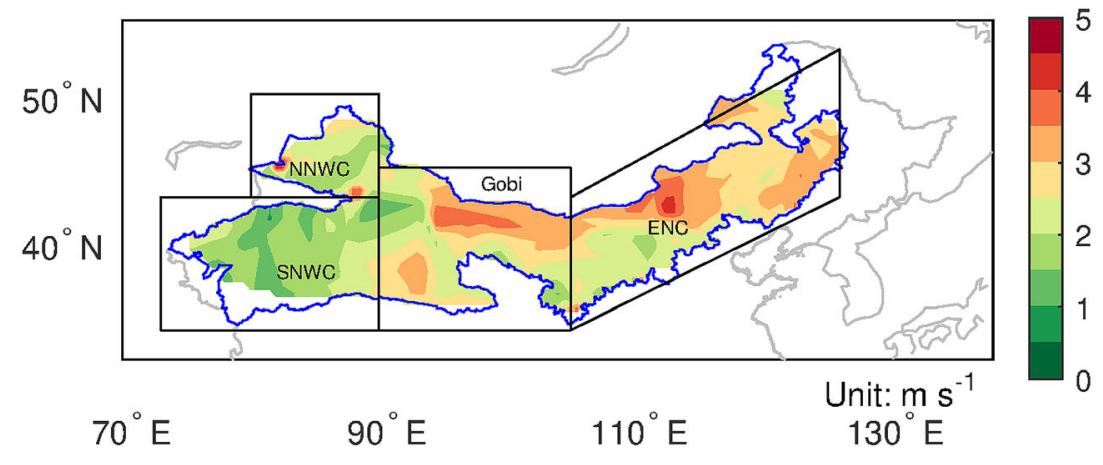

(b) Trend in mean wind speed

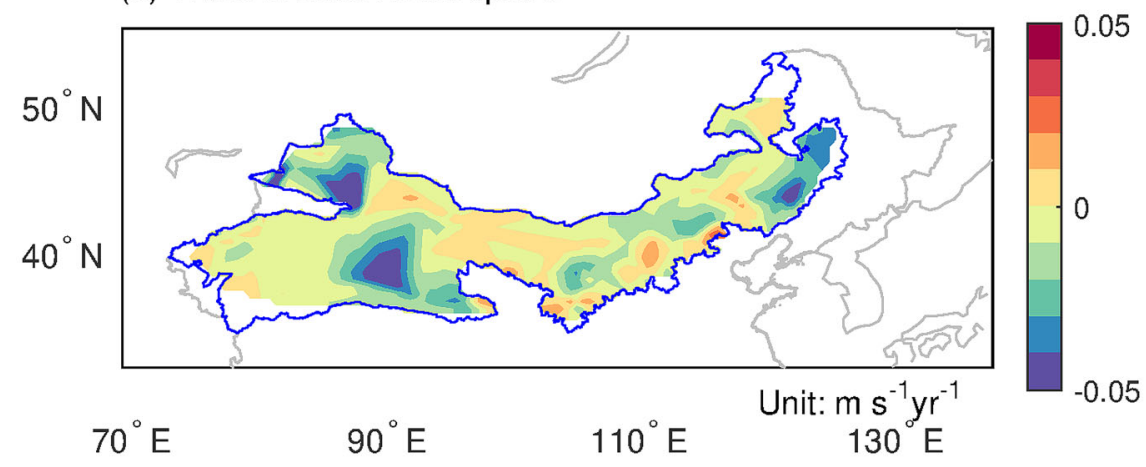

(c) Trend in mean wind speed $\left(>=5 \mathrm{~m} \mathrm{~s}^{-1}\right)$

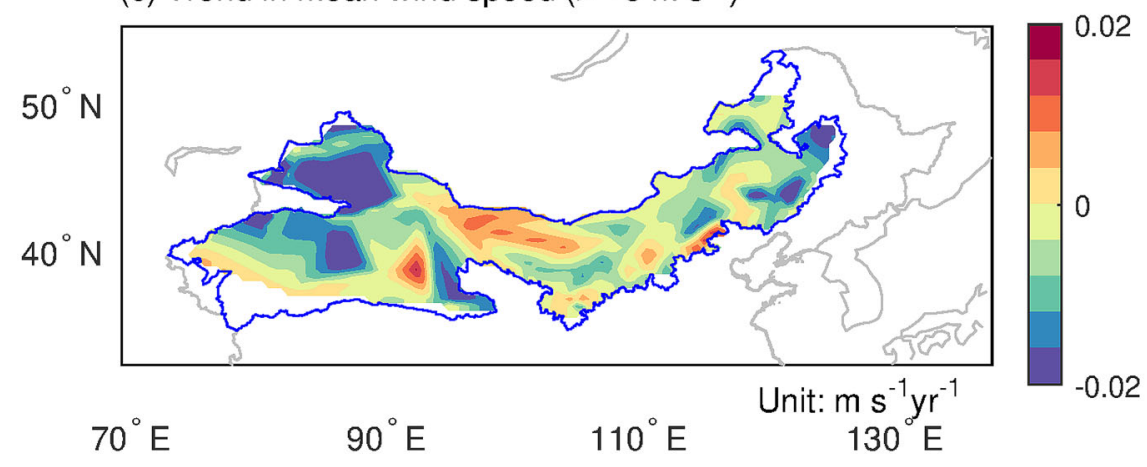

(d) Trend in wind frequency $\left(>=5 \mathrm{~m} \mathrm{~s}^{-1}\right)$

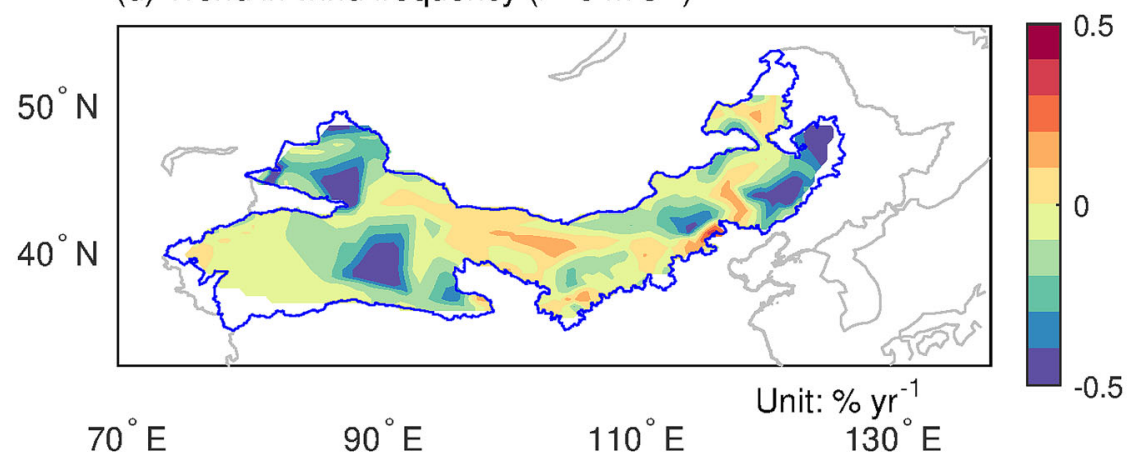

We averaged the mean wind speed in each of the four subregions during 1981-2016. The mean wind speed showed interdecadal changes over the four subregions from
1981 to 2016 (Fig. 3a). The mean wind speed in the SNWC, NNWC, and ENC presented a decreasing trend in spring from 1981 to 2016 by -0.10 to $-0.14 \mathrm{~m} \mathrm{~s}^{-1} 10$ 
year ${ }^{-1}$, significant at the $95 \%$ confidence level (Table 1). However, the mean wind speed in the Gobi Desert decreased from 1981 to 1992 and increased from 1992 to 2012. Subsequently, the mean wind speed in the Gobi Desert decreased during 2013-2016. As a result, the linear trends in the wind speed in the Gobi Desert were $-0.42 \mathrm{~m} \mathrm{~s}^{-1} 10$ year $^{-1}$ during 1981-1992 and $0.13 \mathrm{~m} \mathrm{~s}^{-1} 10$ year $^{-1}$ during 1992-2012, respectively, which are significant at the $95 \%$ confidence level. Because of the dominant role of the decreasing trend in the mean wind speed in 1981-1992, however, the linear trend in the mean wind speed in the Gobi Desert was negative by $-0.04 \mathrm{~m} \mathrm{~s}^{-1} 10$ year $^{-1}$ during 1981-2016, significant at the $95 \%$ confidence level.

\subsection{Changes in Extreme Wind Speed}

We first examined the spatial distribution of trend in the mean wind speed of heavy wind in northern China during 1981-2016. The heavy wind was defined as wind speed exceeding $5 \mathrm{~m} \mathrm{~s}^{-1}$. Figure $2 \mathrm{c}$ shows the spatial distribution of trend in the mean wind speed of heavy wind during 1981-2016 in northern China. The largest negative trend was located over the SNWC, NNWC, southern Gobi Desert, and eastern ENC by more than $-0.2 \mathrm{~m} \mathrm{~s}^{-1} 10$ year $^{-1}$. The northern Gobi Desert, however, showed an increasing trend in the mean wind speed of heavy wind by more than $0.1 \mathrm{~m} \mathrm{~s}^{-1}$ per 10 year. Secondly, the spatial distribution of trend in heavy wind frequency in northern China is shown in Fig. $2 d$. As seen in the figure, the
Fig. 3 Time series of mean wind speed (a), mean wind speed of heavy wind (b), and heavy wind frequency (c) during spring in the southern Northwest China (SNWC), northern Northwest China (NNWC), Gobi Desert, and eastern northern China (ENC) from 1981 to 2016. The straight line depicts the linear trend in mean wind speed (a), mean wind speed of heavy wind (b), and heavy wind frequency (c) in the Gobi Desert (a) Mean wind speed

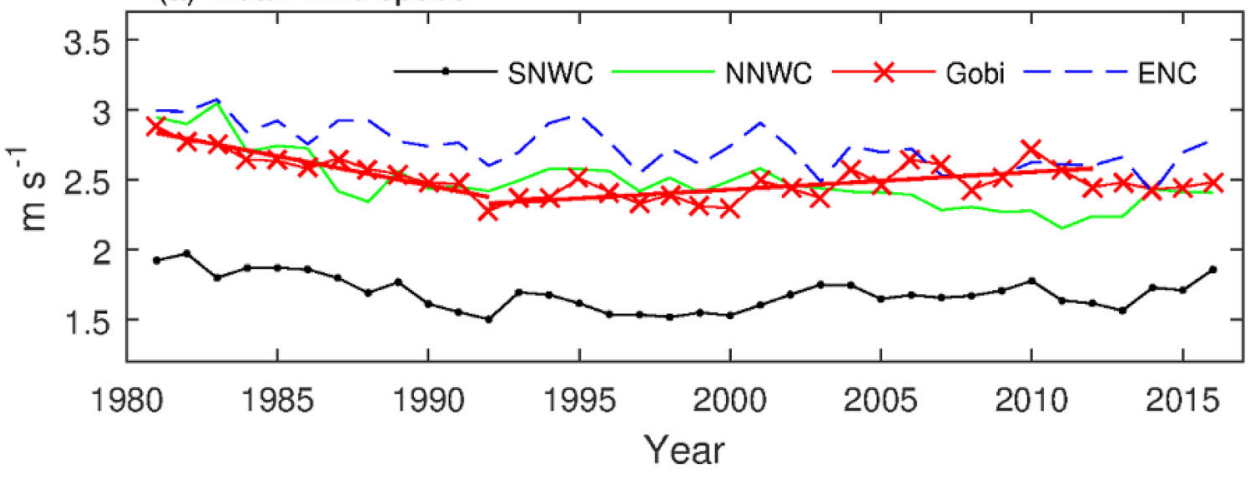

(b) Mean wind speed $\left(>=5 \mathrm{~m} \mathrm{~s}^{-1}\right)$

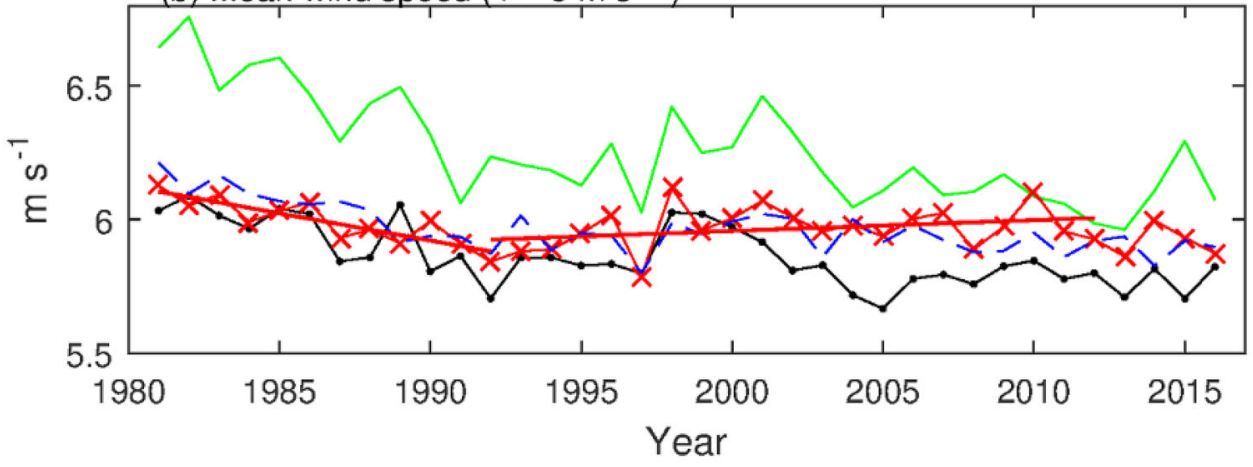

(c) Heavy wind frequency $\left(>=5 \mathrm{~m} \mathrm{~s}^{-1}\right)$

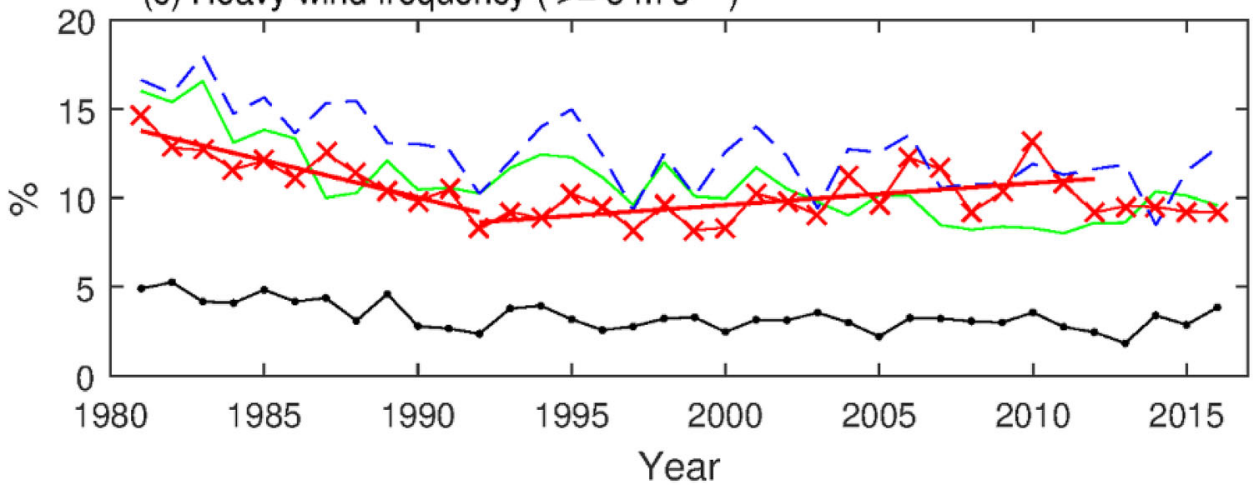


Table 1 Trends in mean wind speed, mean wind speed of heavy wind, heavy wind frequency, and wind erosion force in spring over northern China during 1981-2016

\begin{tabular}{|c|c|c|c|c|}
\hline & $\begin{array}{l}\text { Southern Northwest China } \\
\text { (SNWC) }\end{array}$ & $\begin{array}{l}\text { Northern Northwest China } \\
\text { (NNWC) }\end{array}$ & $\begin{array}{l}\text { Gobi } \\
\text { Desert }\end{array}$ & $\begin{array}{l}\text { Eastern Northern China } \\
\text { (ENC) }\end{array}$ \\
\hline Mean wind speed & $-0.03^{*}$ & $-0.14^{*}$ & $-0.04^{*}$ & $-0.11^{*}$ \\
\hline $\begin{array}{l}\text { Mean wind speed of heavy } \\
\text { wind }\end{array}$ & $-0.07^{*}$ & $-0.14^{*}$ & -0.02 & $-0.06^{*}$ \\
\hline Heavy wind frequency & $-0.45^{*}$ & $-1.61^{*}$ & $-0.6^{*}$ & $-1.40^{*}$ \\
\hline Wind erosion force & $-4.7^{*}$ & $-78.2^{*}$ & $-6.9^{*}$ & $-20.7^{*}$ \\
\hline
\end{tabular}

Units: $\mathrm{m} \mathrm{s}^{-1} 10$ year $^{-1}, \% 10$ year $^{-1}$, and $\mathrm{m}^{3} \mathrm{~s}^{-3} 10$ year $^{-1}$ are for mean wind speed, heavy wind frequency, and wind erosion force, respectively

*Significant at the $95 \%$ confidence level

frequency of heavy wind significantly decreased in the NNWC, eastern SNWC, and ENC by $5 \%$ per 10 year. In the meantime, heavy wind frequency weakly decreased in western SNWC by less than $1 \%$ per 10 year. In contrast to the decreasing trends in heavy wind frequency over these regions, the Gobi Desert had an increasing trend in heavy wind frequency by more than $1 \%$ per 10 year as well as in the mean wind speed of heavy wind in the Gobi Desert.

Figure $3 \mathrm{~b}$ shows the time series of mean wind speed of heavy wind over the four subregions during 1981-2016. In the SNWC, NNWC, and ENC, the mean wind speed of heavy wind decreased from 1981 to the end of the $1990 \mathrm{~s}$ and then increased during 1998-2003. Thereafter the mean wind speed of heavy wind retained a decreasing trend during 2004-2016 over these subregions. As a result, the trend in the mean wind speed of heavy wind was -0.07 , -0.14 , and $-0.06 \mathrm{~m} \mathrm{~s}^{-1}$ per 10 year in the SNWC, NNWC, and ENC during 1981-2016, respectively (Table 1). The Gobi Desert presented for 1981-1992 a decreasing trend, for 1992-2012 an increasing trend, and thereafter a weakly decreasing trend in mean wind speed of heavy wind. The linear trends were $-0.20 \mathrm{~m} \mathrm{~s}^{-1} 10$ year ${ }^{-1}$ during 1981-1992 and $0.04 \mathrm{~m} \mathrm{~s}^{-1} 10$ year $^{-1}$ during 1992-2012, respectively. Because of the dominant role of the decreasing trend in the mean wind speed of heavy wind during 1981-1992, the trend in the mean wind speed of heavy wind was $-0.02 \mathrm{~m} \mathrm{~s}^{-1}$ per 10 year in the Gobi Desert during 1981-2016 (Table 1).

Figure $3 \mathrm{c}$ shows the regional mean of heavy wind frequency in northern China during 1981-2016. The heavy wind frequency in the SNWC, NNWC, and ENC decreased significantly from 1981 to the end of the 1990s and thereafter retained a weak decreasing trend from the end of the 1990 s to 2016 . As a result, the trend of heavy wind frequency during 1981-2016 was - 0.45, - 1.61, and $-1.40 \%$ per 10 year in the SNWC, NNWC, and ENC, respectively, significant at the $95 \%$ confidence level. However, the heavy wind frequency in the Gobi Desert showed a decreasing trend from 1981 to 1992 and thereafter presented an increasing trend during 1992-2012. The linear trends in the heavy wind frequency in the Gobi Desert were $-4.2 \% 10$ year $^{-1}$ during 1981-1992 and $1.2 \% 10$ year $^{-1}$ during 1992-2012, respectively, which are significant at the $95 \%$ confidence level. Because of the dominant role of the decreasing trend in the heavy wind frequency during 1981-1992, the linear trend in heavy wind frequency in the Gobi Desert was $-0.6 \% 10$ year $^{-1}$ during 1981-2016, significant at the 95\% confidence level.

\subsection{Changes in Wind Erosion Force}

Figure $4 \mathrm{a}$ shows the spatial distribution of climatological wind erosion force during 1981-2016 in northern China. The results show that there was high wind erosion force from the Gobi Desert to the western ENC along the boundary between China and Mongolia at above $100 \mathrm{~m}^{3} \mathrm{~s}^{-3}$. The wind erosion force was $20-100 \mathrm{~m}^{3} \mathrm{~s}^{-3}$ over the eastern ENC and NNWC and less than $20 \mathrm{~m}^{3} \mathrm{~s}^{-3}$ over the SNWC. We averaged wind erosion force in each of the four subregions. The average of wind erosion force in the SNWC, NNWC, Gobi Desert, and ENC was 28, 200, 147 , and $80 \mathrm{~m}^{3} \mathrm{~s}^{-3}$, respectively. The highest wind erosion force suggests that the highest effect of wind speed on wind erosion occurred in the NNWC and Gobi Desert, which is consistent with the largest wind erosion occurring in these subregions during 1990-2016 (Chi et al. 2019).

Figure $4 \mathrm{~b}$ shows the spatial distribution of trend in wind erosion force in northern China during 1981-2016. There was a large area of decreasing trend in wind erosion force in northern China. The wind erosion force decreased in the SNWC and Gobi Desert by less than $-20 \mathrm{~m}^{3} \mathrm{~s}^{-3}$ per 10 year and in the NNWC and ENC by more than $-20 \mathrm{~m}^{3}$ $\mathrm{s}^{-3}$ per 10 year during 1981-2016. However, there are some areas in northern China with positive trends in wind erosion force, including the area along the boundary between the NNWC and the Gobi Desert and the central 
(a) Climatology of wind erosion force

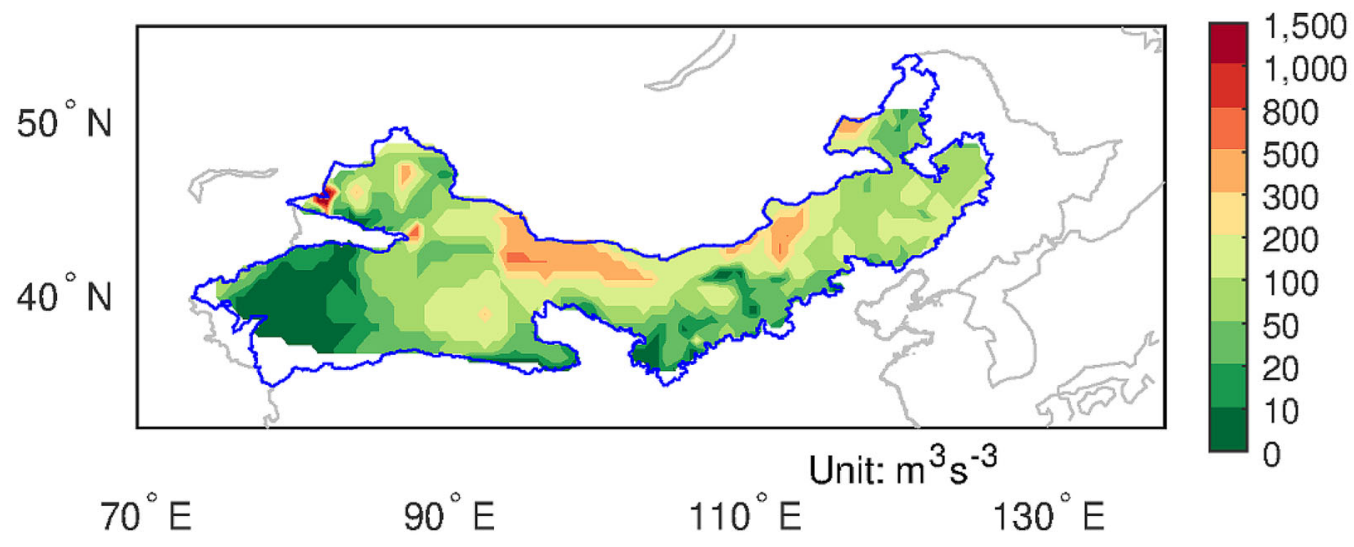

(b) Trend in wind erosion force

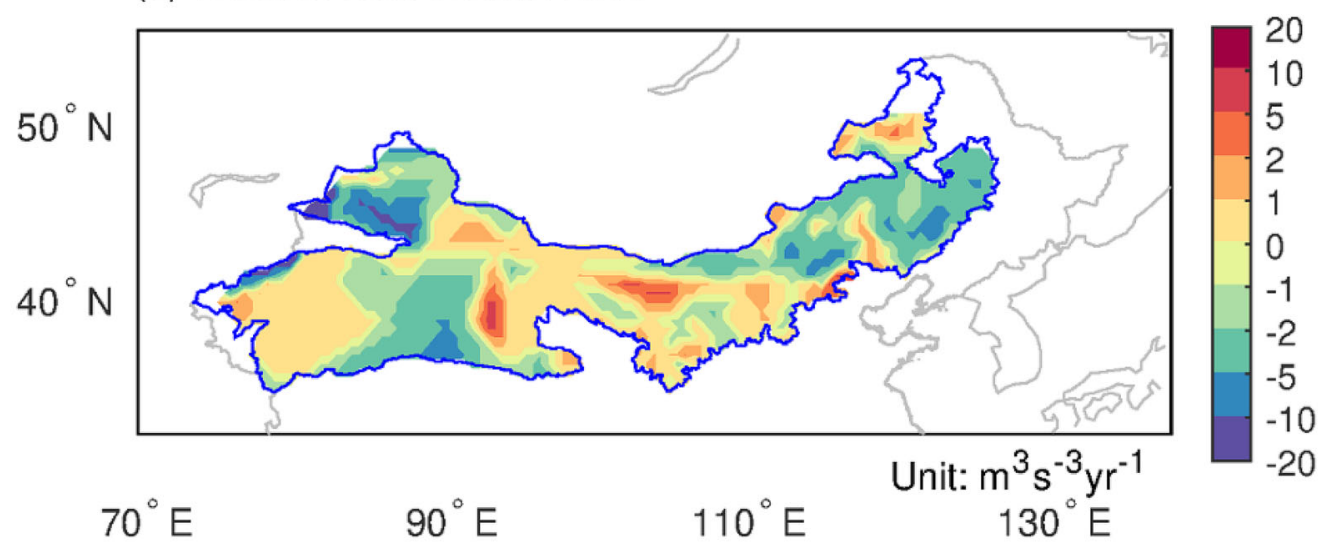

(c) Wind erosion force in northern China

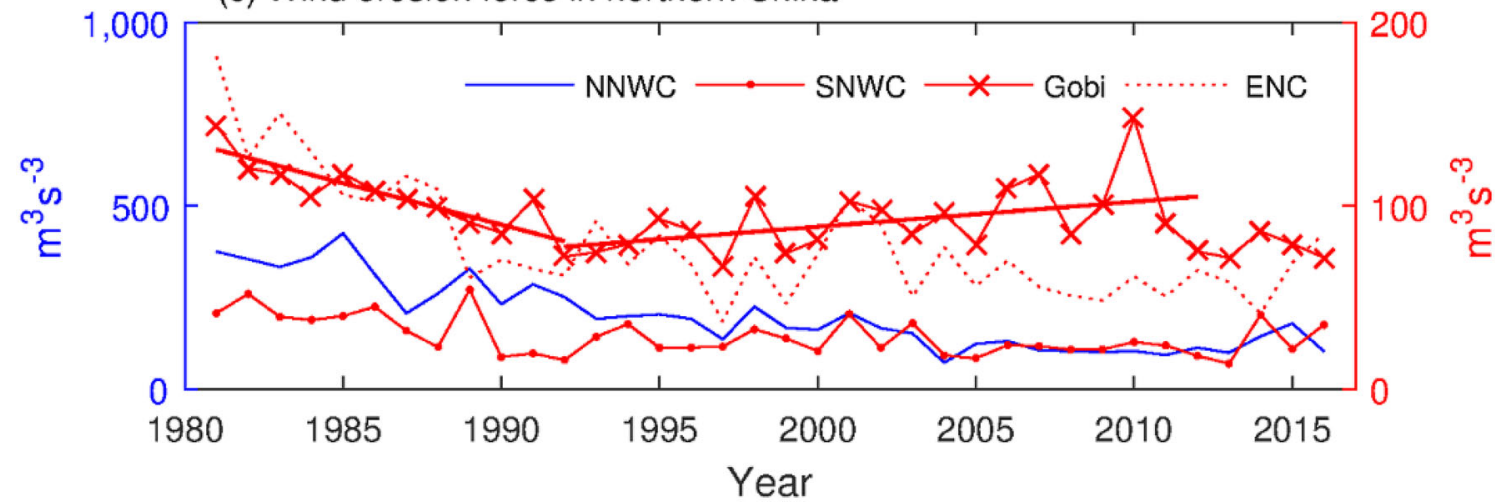

Fig. 4 Spatial distribution of climatological wind erosion force (a) and trend in wind erosion force (b) in northern China during spring from 1981 to 2016. Segment (c) shows the time series of spring wind erosion force in the southern Northwest China (SNWC),

northern China. We averaged the wind erosion force in the four subregions during 1981-2016 (Fig. 4c). The wind erosion force decreased from 1981 to the end of the 1990s over three surbregions (SNWC, NNWC, and ENC) in spring, followed by a stable wind erosion force in 2000-2016. As a result, the wind erosion force showed northern Northwest China (NNWC), Gobi Desert, and eastern northern China (ENC) during 1981-2016. The straight line in c depicts the linear trend in wind erosion force in the Gobi Desert

decreasing trends by $-4.7,-78.2$, and $-20.7 \mathrm{~m}^{3} \mathrm{~s}^{-3}$ per 10 year for the SNWC, NNWC, and ENC during 1981-2016, respectively (Table 1). This decreasing trend means that the influence of wind speed on wind erosion continually decreased in the SNWC, NNWC, and ENC during 1981-2016. In contrast to the decreasing wind 


\section{(a) Climatology of climatic factor}

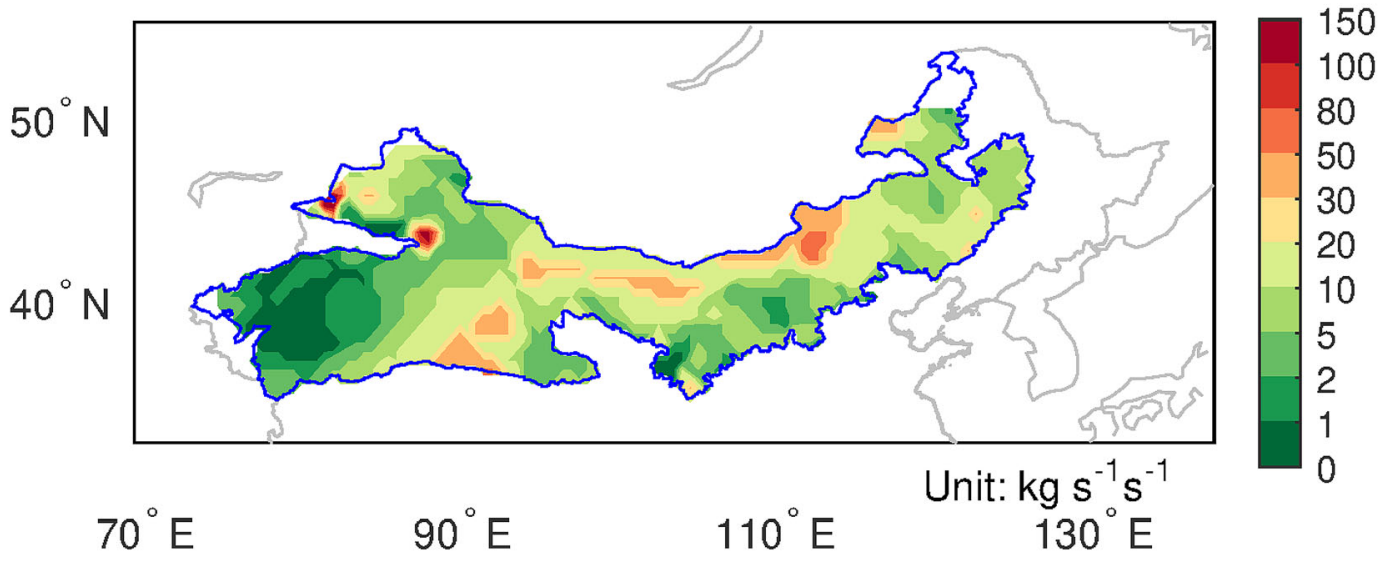

(b) Trend in climatic factor
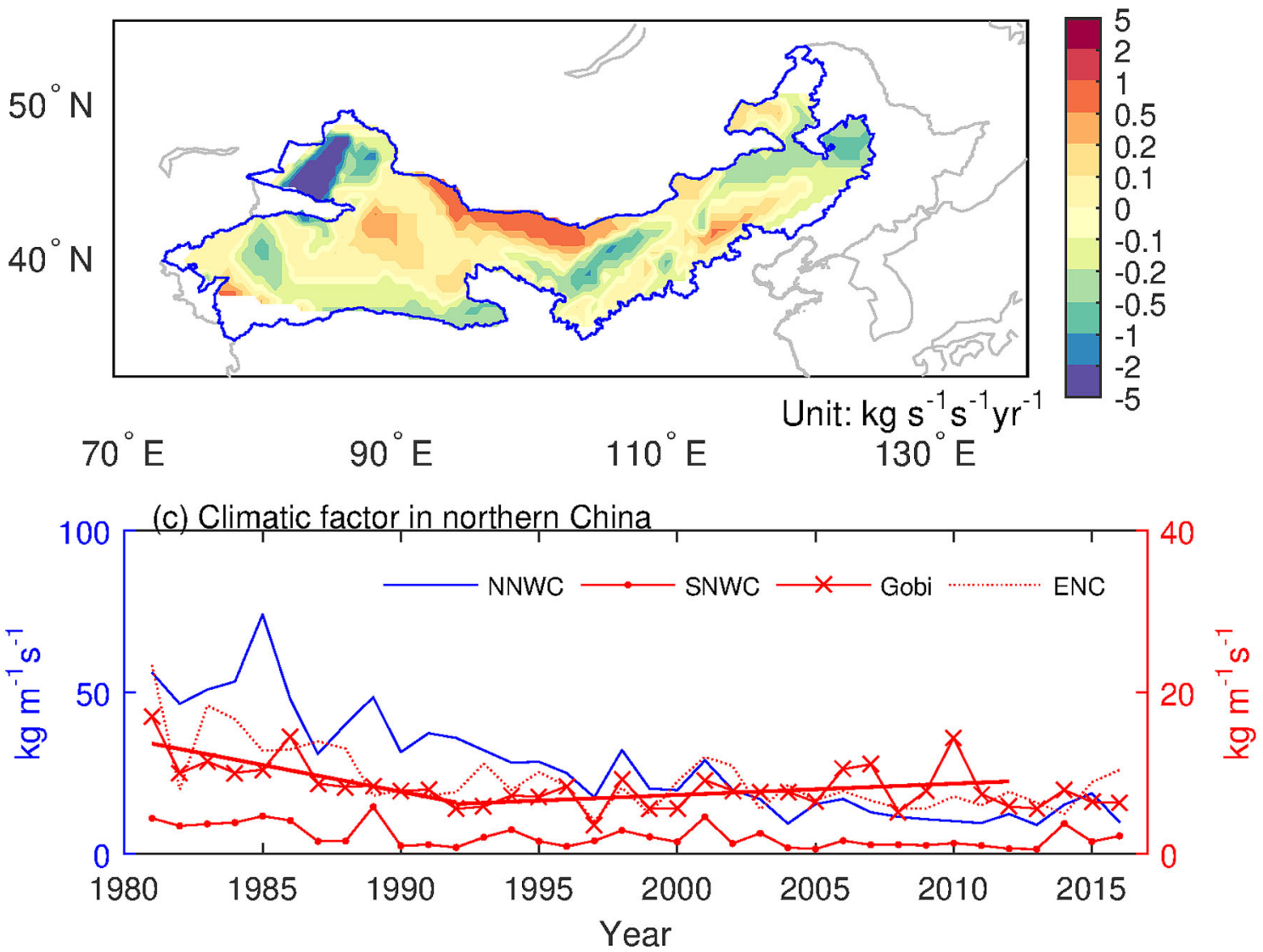

Fig. 5 Spatial distribution of climatological climatic factor (a) and trend in climatic factor (b) in northern China during spring from 1981 to 2016. (c) Shows the time series of spring climatic factor over the southern Northwest China (SNWC), northern Northwest China

erosion force in the SNWC, NNWC, and ENC, the wind erosion force in the Gobi Desert showed a decreasing trend from 1981 to 1992 , but thereafter presented an increasing trend during 1992-2012. The linear trends in the wind erosion force in the Gobi Desert were $-45.3 \mathrm{~m}^{3} \mathrm{~s}^{-3}$
(NNWC), Gobi Desert, and eastern northern China (ENC) during 1981-2016. The straight line depicts the linear trend in the climatic factor over the Gobi Desert

10 year $^{-1}$ during $1981-1992$ and $13.7 \mathrm{~m}^{3} \mathrm{~s}^{-3} 10$ year $^{-1}$ during 1992-2012, respectively, which were significant at the $95 \%$ confidence level. However, because of the dominant role of the decreasing trend in the wind erosion force during 1981-1992, the trend in the wind erosion force in 
the Gobi Desert during 1981-2016 was $-6.9 \mathrm{~m}^{3} \mathrm{~s}^{-3}$ per 10 year, significant at the $95 \%$ confidence level, indicating a decrease in the influence of wind speed on wind erosion in the Gobi Desert during 1981-2016.

\section{Discussion}

This study has indicated that the wind erosion force presented a long-term decreasing trend in the SNWC, NNWC, and ENC regions during 1981-2016. In the Gobi Desert, wind erosion force presented a decreasing trend for 1981-1992, an increasing trend for 1992-2012, and thereafter a weakly decreasing trend. Besides wind speed, there are additional factors related to climate change that influence wind erosion through changing soil erodibility. Therefore, the following sections explore the role of soil wetness, snow cover, and vegetation cover in wind erosion.

\subsection{The Influence of Soil Wetness and Snow Cover on Wind Erosion}

To examine the contribution of soil wetness and snow cover to wind erosion, we calculated the climatic factor $(C F)$ in the RWEQ model in northern China, which represent effects of wind speed, soil wetness, and snow cover on wind erosion. The $C F$ climatology resembles that of the wind erosion force in northern China during 1981-2016, with high values exceeding $30 \mathrm{~kg} \mathrm{~m}^{-1} \mathrm{~s}^{-1}$ over the areas between the Gobi Desert and the NNWC and along the boundary between China and Mongolia and with low ones less than $5 \mathrm{~kg} \mathrm{~m}^{-1} \mathrm{~s}^{-1}$ in the SNWC and southern and eastern ENC (Fig. 5a). The average of $C F$ was 3, 23, 19, and $9 \mathrm{~kg} \mathrm{~m}^{-1} \mathrm{~s}^{-1}$ in the SNWC, NNWC, Gobi Desert, and ENC, respectively. Subsequently, we examined the spatial feature of the trend in the $C F$ in northern China during 1981-2016 (Fig. 5b). There was an increasing trend in the $C F$ along the boundary between the NNWC and northern Gobi Desert by more than $1 \mathrm{~kg} \mathrm{~m}^{-1} \mathrm{~s}^{-1}$ per 10 year. There also were areas of negative trends in the $C F$ over the ENC, southern Gobi Desert, and western NNWC during $1981-2016$ by $-2 \mathrm{~kg} \mathrm{~m}^{-1} \mathrm{~s}^{-1}$ per 10 year. Figure $5 \mathrm{c}$ shows the time series of $C F$ in the four subregions during 1981-2016. The $C F$ decreased from 1981 to the end of the 1990 s over the four surbregions. Although the $C F$ retained a low value in 2000-2016 in the SNWC, NNWC, and ENC, the $C F$ in the Gobi Desert presented an increasing trend during 1992-2012 compared to 1981-1992. By comparing the spatial distributions of climatology and trend of $C F$ with those of wind erosion force, the similar pattern between the wind erosion force and the $C F$ provides evidence that soil wetness and snow cover exerted a weaker influence on wind erosion in northern China compared to wind speed during 1981-2016.

\subsection{The Influence of Vegetation Cover on Wind Erosion}

Changes in vegetation cover are driven by anthropogenic activities, as well as natural climate change. The Chinese government has launched ecological projects to reduce wind erosion in northern China-for example, the ThreeNorth Shelterbelt Development Program (1978-2050), Beijing-Tianjin Sand Source Control Program (2001-2010/2013-2022) (Bryan et al. 2018). These ecological projects caused an increase in vegetation cover (Liu et al. 2018) and hence induced a decrease of wind erosion (Huang et al. 2018; Chi et al. 2019; Zhao et al. 2020). For instance, the ecological projects in the Beijing-Tianjin sand source region caused a decrease of wind erosion modulus by 3.77 million tons during 2000-2015 of which approximately $70 \%$ was prompted by the gradual transition from desert to sparse grassland (Zhao et al. 2020). Chi et al. (2019) showed a decreasing trend by $0.71 \mathrm{t} \mathrm{ha}^{-1}$ year $^{-1}$ in wind erosion modulus because of ecological projects during 2000-2010. Huang et al. (2018) indicated that the Three-North Shelterbelt Development Program and other ecological programs were related to a decrease of wind erosion by $11-15 \%$ at a local scale during $1970-2015$.

Besides the influence of vegetation cover on wind erosion related to anthropogenic activities, we examined the influence of vegetation cover caused by natural climate change on wind erosion. Because the SNWC and Gobi Desert have a very low vegetation cover (Yang et al. 2018), we only examined long-term trends in the NDVI over the NNWC and ENC. The NDVI showed a long-term increasing trend in the spring over the ENC by $0.37 \%$ per 10 year during 1982-2015, significant at the 95\% confidence level (Fig. 6b). The increasing trend in vegetation cover in the ENC supports the decrease of wind erosion caused by ecological projects (Huang et al. 2018; Chi et al. 2019; Zhao et al. 2020). The increasing trend in the NDVI indicates that vegetation cover related to climate change played a role in the long-term decreasing trend in wind erosion in the ENC. However, the NDVI in the NNWC did not have a significant long-term trend during 1981-2015, implying a weak contribution of vegetation cover to longterm changes in wind erosion in the NNWC during 1982-2015 (Fig. 6a). 
Fig. 6 Time series of Normalized Deviation of Vegetation Index (NDVI) over northern Northwest China (NNWC) (a) and eastern northern China (ENC) (b) from 1982 to 2015 . The linear trend in NDVI was significant at the 95\% confidence level in (b) and is indicated by a dashed straight line
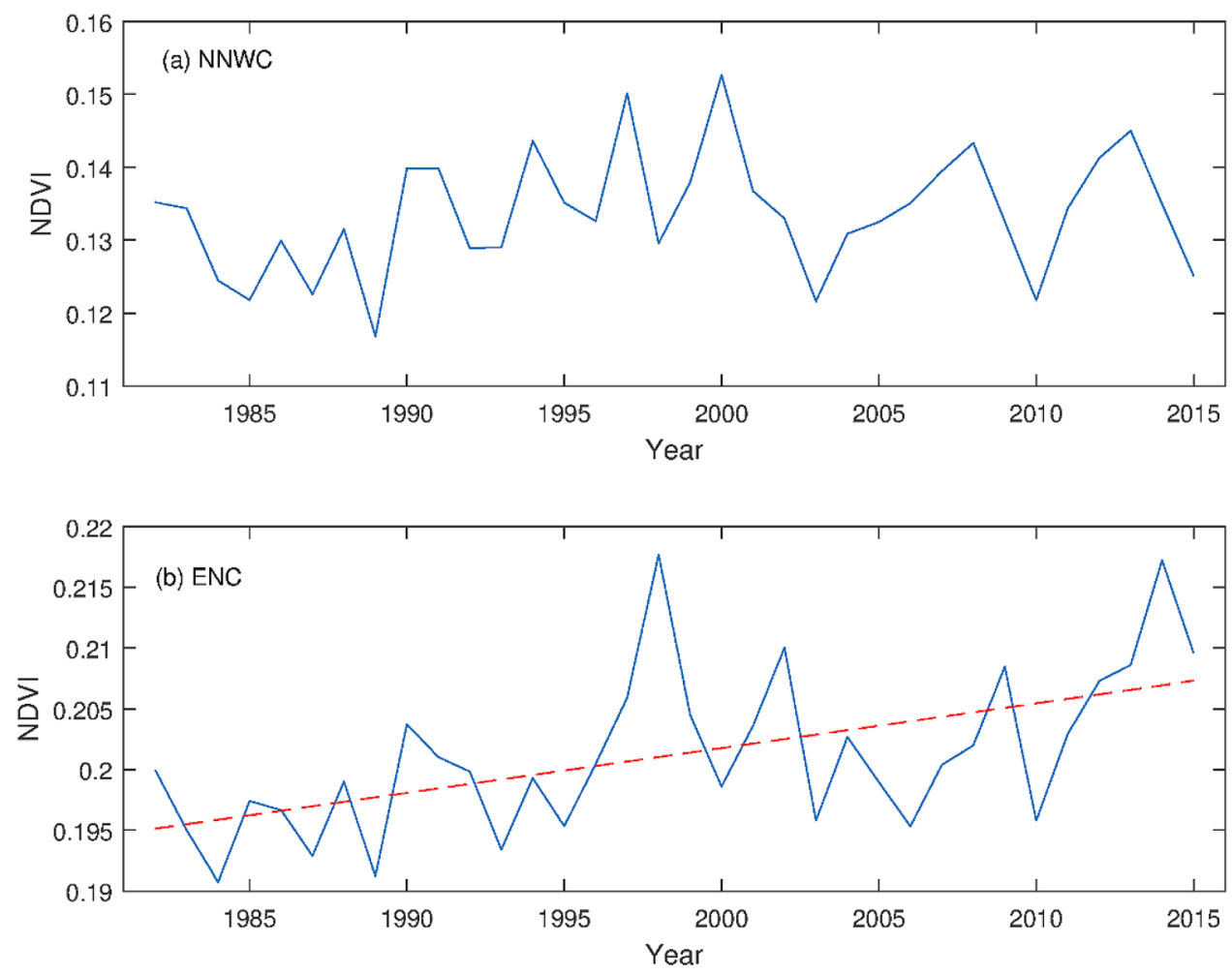

\section{Conclusion}

Wind erosion is often greatly influenced by wind speed. In this study, we used wind erosion force, represented by wind factor from the Revised Wind Erosion Equation (RWEQ) model, to study the influence of wind speed on wind erosion in northern China from 1981 to 2016. The spring wind speed in southern Northwest China (SNWC), northern Northwest China (NNWC), and eastern northern China (ENC) showed a decreasing trend from 1981 to 2016 by $-0.03,-0.14$, and $-0.11 \mathrm{~m} \mathrm{~s}^{-1}$ per 10 year, respectively. The heavy wind frequency presented a decreasing trend as well as mean wind speed by $0.45 \%, 1.61 \%$, and $1.40 \%$ per 10 year in the SNWC, NNWC, and ENC, respectively. As a result, wind erosion force significantly decreased in the NNWC and weakly decreased in the SNWC and ENC during spring from 1981 to 2016 by $-78.2,-4.7$, and $-27.1 \mathrm{~m}^{3} \mathrm{~s}^{-3}$ per 10 year, respectively, implying a decreasing influence of wind speed on wind erosion in 1981-2016 over these subregions. In comparison with the SNWC, NNWC, and ENC, the wind speed and heavy wind frequency in the Gobi Desert presented a decreasing trend from 1981 to 1992 and thereafter an increasing trend from 1992 to 2012, resulting in an increase in the influence of wind speed on wind erosion in the Gobi Desert in 1992-2012 compared to 1981-1992. However, because of the dominant role of the decreasing trends in wind speed and heavy wind frequency, the trend in wind erosion force in the Gobi Desert is $-6.9 \mathrm{~m}^{3} \mathrm{~s}^{-3}$ per 10 year during 1981-2016, indicating a decrease in the influence of wind speed on wind erosion in the Gobi Desert during 1981-2016.

We also examined the influence of soil wetness, snow cover, and vegetation cover on wind erosion in northern China. We calculated climatic factor $(C F)$ in the RWEQ model in northern China, which represent effects of wind speed, soil wetness, and snow cover on wind erosion. By comparing the spatial distributions of climatology and the trend of $C F$ with those of wind erosion force, the similar patterns between wind erosion force and $C F$ provide evidence that soil wetness and snow cover exerted a weaker influence on wind erosion in northern China compared to wind speed during 1981-2016. In the meantime, the increasing trend in the vegetation cover in the ENC supports a decrease of wind erosion in the ENC during 1982-2015. However, the vegetation cover had a weak contribution to wind erosion reduction in the NNWC during 1982-2015.

Acknowledgements This work was financially supported by the Science Fund for Creative Research Groups of the National Natural Science Foundation of China (Grant No. 41621061); the National Natural Science Foundation of China (Grants Nos. 41630747, 41671501, 41571039); and the State Key Laboratory of Earth Surface Processes and Resource Ecology (Grant No. 2017-ZY-05).

Open Access This article is licensed under a Creative Commons Attribution 4.0 International License, which permits use, sharing, 
adaptation, distribution and reproduction in any medium or format, as long as you give appropriate credit to the original author(s) and the source, provide a link to the Creative Commons licence, and indicate if changes were made. The images or other third party material in this article are included in the article's Creative Commons licence, unless indicated otherwise in a credit line to the material. If material is not included in the article's Creative Commons licence and your intended use is not permitted by statutory regulation or exceeds the permitted use, you will need to obtain permission directly from the copyright holder. To view a copy of this licence, visit http://creativecommons. org/licenses/by/4.0/.

\section{References}

Allen, R.G., L.S. Pereira, D. Raes, and M. Smith. 1998. Crop evapotranspiration-guidelines for computing crop water requirements. FAO irrigation and drainage paper 56. Rome, Italy: Food and Agriculture Organization of the United Nations (FAO).

Bryan, B.A., L. Gao, Y. Ye, X. Sun, J.D. Connor, N.D. Crossman, S.S. Mark, J. Wu, et al. 2018. China's response to a national landsystem sustainability emergency. Nature 559(7713): 193-204.

Buschiazzo, D.E., and T.M. Zobeck. 2008. Validation of WEQ, RWEQ and WEPS wind erosion for different arable land management systems in the Argentinean Pampas. Earth Surface and Processes Landform 33(12): 1839-1850.

Chi, W., Y. Zhao, W. Kuang, and H. He. 2019. Impacts of anthropogenic land use/cover changes on wind erosion in China. Science of the Total Environment 668: 204-215.

China, People's Republic of. Ministry of Water Resources. 2013. Bulletin of first national census for soil and water conservation. Soil and Water Conservation in China 10: 2-11 (in Chinese).

Dong, Y., and G. Kang. 1994. Study on the wind erosion climatic erosivity in arid and semi-arid areas in China. Journal of Soil and Water Conservation 8(3): 1-7 (in Chinese).

Du, H., T. Wang, and X. Xue. 2017. Potential wind erosion rate response to climate and land- use changes in the watershed of the Ningxia-Inner Mongolia reach of the Yellow River, China, 1986-2013. Earth Surface Processes and Landforms 42(13): 1923-1937.

Elliott, D.L. 1979. Adjustment and analysis of data for regional wind energy assessments. In Proceedings of the Workshop on Wind Climate, 12-13 November 1979, ed. K.C. Mehta, 121-131. Asheville, NC: Electric Power Research Institute and The National Science Foundation.

FAO (Food and Agriculture Organization of the United Nations). 1979. A provisional methodology for soil degradation assessment. Rome, Italy: FAO.

Fryrear, D., A. Saleh, J. Bilbro, H. Schomberg, J. Stout, and T. Zobeck. 1998. Revised wind erosion equation (RWEQ). Technical bulletin no. 1. Lubbock, TX: Southern Plains Area Cropping Systems Research Laboratory, Wind Erosion and Water Conservation Research Unit, United States Department of Agriculture-Agricultural Research Service.

Fryrear, D.W., M.M. Wassif, S.E. Tadrus, and A.A. Ali. 2008. Dust measurements in the Egyptian northwest coastal zone. Transactions of the ASABE [American Society of Agricultural and Biological Engineers] 51(4): 1255-1262.

Guo, Z., T.M. Zobeck, J.E. Stout, and K.L. Zhang. 2012. The effect of wind averaging time on wind erosivity estimation. Earth Surface Processes and Landforms 37(7): 797-802.

Guo, Z., T.M. Zobeck, K. Zhang, and F. Li. 2013. Estimating potential wind erosion of agricultural lands in northern China using the revised wind erosion equation and geographic information systems. Journal of Soil and Water Conservation 68(1): 13-21.

Han, L. 2019. Temporal and spatial variation characteristics of wind speed and its influence on wind erosion climatic erosivity in the wind erosion region of Northern China. Yantai, China: Ludong University (in Chinese).

Huang, L., P. Zhu, T. Xiao, and G. Gong. 2018. The sand fixation effects of Three-North Shelter Forest Program in recent 35 years. Scientia Geographica Sinica 38(4): 600-609 (in Chinese).

Jarrah, M., S. Maye, J. Tatarko, R. Funk, and K. Kuka. 2020. A review of wind erosion models: Data requirements, processes, and validity. CATENA 187: Article 104388.

Li, P., L. Liu, J. Wang, Z. Wang, X. Wang, Y. Bai, and S. Chen. 2018. Wind erosion enhanced by land use changes significantly reduces ecosystem carbon storage and carbon sequestration potentials in semiarid grasslands. Land Degradation \& Development 29(10): 3469-3478.

Liu, J., J. Ning, W. Kuang, X. Xu, S. Zhang, C. Yan, R. Li, S. Wu, et al. 2018. Spatiotemporal patterns and characteristics of landuse change in China during 2010-2015. Acta Geographica Sinica 73(5): 789-802 (in Chinese).

Mao, R., C.-H. Ho, S. Feng, D.-Y. Gong, and Y. Shao. 2013. The influence of vegetation variation on Northeast Asian dust activity. Asia-Pacific Journal of Atmospheric Sciences 49(1): 87-94.

Pinzon, J.E., and C.J. Tucker. 2014. A non-stationary 1981-2012 AVHRR NDVI3g time series. Remote Sensing 6(8): 6929-6960.

Shao, Y., M. Klose, and K.H. Wyrwoll. 2013. Recent global dust trend and connections to climate forcing. Journal of Geophysical Research: Atmospheres 118(19): 11107-11118.

Shen, Y., C. Zhang, X. Wang, X. Zou, and L. Kang. 2018. Statistical characteristics of wind erosion events in the erosion area of northern China. CATENA 167: 399-410.

Shi, P., P. Yan, Y. Yuan, and M.A. Nearing. 2004. Wind erosion research in China: past, present and future. Progress in Physical Geography-Earth and Environment 28(3): 366-386 (in Chinese).

Tucker, C.J., J.E. Pinzon, M.E. Brown, D.A. Slayback, E.W. Pak, R. Mahoney, E.F. Vermote, and N. Saleous. 2005. An extended AVHRR-8 km NDVI dataset compatible with MODIS and SPOT vegetation NDVI data. International Journal of Remote Sensing 26(20): 4485-4498.

Van Pelt, R.S., T.M. Zobeck, K.N. Potter, J.E. Stout, and T.W. Popham. 2004. Validation of the wind erosion stochastic simulator (WESS) and the revised wind erosion equation (RWEQ) for single events. Environmental Modelling \& Software 19(2): 191-198.

Wagner, L.E. 2013. A history of wind erosion prediction models in the United States Department of Agriculture: The Wind Erosion Prediction System (WEPS). Aeolian Research 10: 9-24.

Wang, J. 2007. Textbook of Chinese geography. Beijing, China: Higher Education Press.

Wu, Z., M. Wang, H. Zhang, and Z. Du. 2019. Vegetation and wind erosion dynamics of sandstorm control programs in the agropastoral transitional zone of northern China. Frontiers of Earth Science 13(2): 430-443.

Yang, F.B., and C.H. Lu. 2016. Assessing changes in wind erosion climatic erosivity in China's dryland region during 1961-2012. Journal of Geographical Sciences 26(9): 1263-1276.

Yang, L., J. Kun, S. Liang, M. Liu, X. Wei, Y. Yao, X. Zhang, and D. Liu. 2018. Spatio-temporal analysis and uncertainty of fractional vegetation cover change over northern China during 2001-2012 based on multiple vegetation data sets. Remote Sensing 10(4): Article 549.

Zhang, H., J. Fan, W. Cao, W. Harris, Y. Li, W. Chi, and S. Wang. 2018. Response of wind erosion dynamics to climate change and 
human activity in Inner Mongolia, China during 1990 to 2015. Science of the Total Environment 639: 1038-1050.

Zhao, Y., W. Chi, W. Kuang, Y. Bao, and G. Ding. 2020. Ecological and environmental consequences of ecological projects in the
Beijing-Tianjin sand source region. Ecological Indicators 112: Article 106111. 